\title{
PERCEPÇÃO DE JOVENS E ADOLESCENTES SOBRE SAÚDE E QUALIDADE DE VIDA
}

\author{
Young people's perception about health and quality of life \\ Percepción de jóvenes y adolescentes sobre salud y calidad de vida
}

\author{
Uenia da Silva Brito (iD \\ Faculdade de Juazeiro do Norte - FJN - Juazeiro do Norte (CE) - Brasil \\ Elida Mara Braga Rocha iD \\ Faculdade de Juazeiro do Norte - FJN - Juazeiro do Norte (CE) - Brasil
}

\section{RESUMO}

Objetivo: Conhecer a percepção que jovens e adolescentes têm sobre saúde e qualidade de vida. Métodos: Trata-se de um estudo qualitativo, desenvolvido em 2018, em um distrito de Orós, Ceará, Brasil, composto por dez adolescentes e jovens, de 15 a 24 anos de idade, participantes de um grupo religioso católico. Os dados foram obtidos por meio de entrevista semiestruturada utilizando um aplicativo de gravação. Analisaram-se as entrevistas pela técnica de análise de conteúdo, emergindo as categorias temáticas: Percepção de saúde e qualidade de vida; Interesses e contatos com temas relacionados à saúde e qualidade de vida; Programas de saúde para adolescentes e jovens; Uso da Estratégia Saúde da Família (ESF) pelos adolescentes e jovens. Resultados: Os entrevistados possuíam dificuldade em conceituar saúde e qualidade de vida, mas abordaram um entendimento que envolvia alimentação, aspectos físicos e bem-estar. Os adolescentes e os jovens relataram a busca direta de informações sobre a temática, mesmo que não fossem discutidos no domicílio ou o fossem de forma limitada na escola. O entendimento sobre a promoção de saúde é referente aos cuidados básicos, contudo não há reconhecimento de programas de saúde específicos para esse público. Conclusão: A saúde e a qualidade de vida podem ser entendidas pelos adolescentes e jovens como algo positivo e dinâmico, sendo capturadas percepções amplas e diversificadas sobre a temática. Dessa forma, sugere-se que esse assunto seja mais debatido na família, na escola e na Atenção Primária à Saúde.

Descritores: Saúde do Adolescente; Qualidade de Vida; Saúde Pública; Adulto Jovem; Educação em Saúde.

\begin{abstract}
Objective: To know the perception that young people and adolescents have about health and quality of life. Methods: This is a qualitative study composed of ten adolescents and young people, aged 15 to 24 years, participating in a Catholic religious group developed in 2018, in a county of Orós, Ceará, Brazil. Data were obtained through semi-structured interviews using a recording application. The interviews were analyzed through the content analysis technique, emerging the thematic categories: Health perception and quality of life; Interests and contacts with topics related to health and quality of life; Health programs for adolescents and young people; Use of the Saúde da Familia Strategy by adolescents and young people. Results: The interviewees had difficulty in conceptualizing health and quality of life, but approached an understanding that involved feeding, physical aspects, and well-being. Adolescents and young people reported the direct search for information on the subject, even if they were not discussed at home or were in a limited way in school. The understanding of health promotion refers to basic care however; there is no recognition of specific health programs for this public. Conclusion: Health and quality of life can be understood by adolescents and young people as something positive and dynamic, and broad and diverse perceptions on the subject are captured. Thus, it suggests that this subject be more debated in the family, school, and Primary Health Care.
\end{abstract}

Descriptors: Adolescent Health; Quality of Life; Public Health; Young Adult; Health Education.

\section{RESUMEN}

Objetivo: Conocer la percepción de jóvenes y adolescentes sobre salud y calidad de vida. Métodos: Se trata de un estudio cualitativo desarrollado en 2018 en un distrito de Orós, Ceará, Brasil con diez adolescentes y jóvenes entre 15 y 24 años de edad

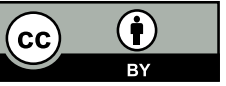


de un grupo de religión católica. Se obtuvieron los datos a través de una entrevista semiestructurada utilizando un aplicativo de grabación. Se analizaron las entrevistas por la técnica de análisis de contenido de las cuales emergieron las siguientes categorías temáticas: Percepción de salud y calidad de vida; Intereses y contactos con temas relacionados con la salud y la calidad de vida; Programas de salud para adolescentes y jóvenes; Uso de la Estrategia Salud de la Familia (ESF) por adolescentes y jóvenes. Resultados: Los entrevistados tenían dificultad de conceptuar la salud y la calidad de vida pero relataron un entendimiento que incluyera la alimentación, los aspectos físicos y el bienestar. Los adolescentes y los jóvenes relataron la búsqueda directa de informaciones sobre el tema aunque no fuera hablado en sus casas o lo era de manera limitada en la escuela. El entendimiento sobre la promoción de la salud se refiere a los cuidados básicos, in embargo, no hay reconocimiento de programas de salud específicos para ese público. Conclusión: La salud y la calidad de vida pueden ser comprendidas por los adolescentes y jóvenes como algo positivo y dinámico con percepciones amplias y diversificadas sobre la temática. De esa manera, sugiérase que se hable más del tema en la familia, la escuela y en la Atención Primaria de Salud.

Descriptores: Salud del Adolescente; Calidad de Vida; Salud Pública; Adulto Joven; Educación en Salud.

\section{INTRODUÇÃO}

A saúde da população brasileira e também o direito à saúde podem ser considerados fenômenos históricos devido a grandes lutas e empasses para a implantação do Sistema Único de Saúde (SUS). Dessa forma, o Conselho Nacional de Saúde, na VIII Conferência Nacional da Saúde, conceitua "saúde" como um termo mais abrangente, que inclui fatores tanto objetivos como subjetivos, dependendo, assim, da visão de cada um para identificação do seu bem-estar e de sua qualidade de vida. Dentre os fatores correspondentes ao conceito de saúde, estão: renda, trabalho, lazer, habitação, transporte, liberdade, acesso a serviços de saúde, educação, alimentação, emprego, meio-ambiente, moradia e posse de terras ${ }^{(1)}$.

Já o conceito de qualidade de vida, apresentado pela Word Health Organization Quality of Life (WHOQOLGroup), se traduz no conhecimento que o sujeito tem de sua posição na vida dentro do contexto de sua cultura e do sistema de valores de onde vive, e em relação a seus objetivos, perspectivas, padrões e apreensões ${ }^{(2)}$. Verifica-se que essa definição se aproxima do conceito de saúde de modo transversal. De acordo com a Constituição Federal de 1988 (art.196), "saúde é direito de todos e dever do Estado, garantido mediante políticas sociais e econômicas que visem à redução do risco de doenças e outros agravos e ao acesso universal e igualitário à ação e serviço para sua promoção, proteção e recuperação"(3).

Existem várias formas de promover saúde e qualidade de vida. Baseando-se em seus respectivos conceitos, a Política Nacional de Promoção da Saúde as concebem de maneira conjunta ou individual( ${ }^{(4)}$. Como um bem público, a saúde é construída nas redes de relações que atuam no melhoramento e criação de políticas públicas do Brasil, colocando os interesses da população como prioridades. E assim, a promoção da saúde constantemente enfrenta tensões em sua própria defesa e garantia, tendo em vista que é composta por várias estratégias e tem por objetivo atender à necessidade da população, garantindo a melhoria da qualidade de vida(5).

Assim, a saúde do adolescente e dos jovens vem se tornando alvo de pesquisas e uma prioridade na criação de programas de saúde em diversos países ${ }^{(6)}$. A Política Nacional de Promoção da Saúde tem como objetivo promover a qualidade de vida e reduzir vulnerabilidade e riscos à saúde relacionados aos seus determinantes e condicionantes, direcionados na perspectiva da população adolescente ${ }^{(7)}$. Porém os programas nacionais brasileiros ainda necessitam ter uma maior cobertura da população adolescente e jovem para obter resultados positivos na atenção à saúde e qualidade de vida desse grupo populacional( ${ }^{(6)}$.

O período da adolescência compreende a faixa etária entre 10 e 19 anos de idade, mas a juventude se estende dos 15 aos 24 anos. Essa faixa etária pode ainda ser subdividida, identificando-se adolescentes jovens de 15 a 19 anos, e adultos jovens de 20 a 24 anos. $\mathrm{Na}$ abordagem conceitual da adolescência, os critérios biológicos, psicológicos e sociais também devem ser considerados, pois a adolescência é a etapa da vida compreendida entre a infância e a fase adulta, marcada por um complexo processo de crescimento e desenvolvimento biopsicossocial( ${ }^{(8)}$.

O processo de transformação inerente ao próprio transcorrer da vida e que ocorre na adolescência e juventude são basicamente mudanças fisiológicas e anatômicas, relacionadas com a puberdade e a integração de um amadurecimento sexual em um modelo pessoal de comportamento, que implica, muitas vezes, em mudanças de ideias e de rumos, o que pode trazer consequências boas ou más. Quanto aos aspectos físico e psíquico, o adolescente passa por transformação que ocorre em seu corpo e mente, independentemente de sua vontade ${ }^{(9)}$.

Nesse contexto, a saúde do adolescente e do jovem é uma temática que deve fazer parte da atenção intersetorial do profissional de saúde, por se tratar de uma etapa diferenciada do ciclo de vida, na qual ocorrem transformações 
comportamentais que podem gerar conflitos internos, físicos, psicossociais e emocionais. Os adolescentes e os jovens apresentam aspectos próprios de comunicação, comportamento e necessidades, constituindo um grupo com diferenças bem específicas de estudo na comunidade médica, científica e social. Portanto, é fundamental o suporte da educação em saúde visando a instrumentalizar o indivíduo para o enfrentamento de condições adversas ${ }^{(10,11)}$. Destaca-se que a produção de saúde para adolescentes e jovens não acontece sem fortes ligações intersetoriais que se interconectem com o setor saúde e com a participação e a cooperação de outros setores e da própria comunidade, notadamente das pessoas jovens e suas famílias, uma vez que as necessidades de saúde ampliada dessa população perpassam as ações do setor saúde ${ }^{(12)}$.

Com o intuito de proteger e assegurar os direitos do adolescente e da criança, no final da década de 1980 , foram instituídos o Programa de Saúde do Adolescente (PROSAD) ${ }^{(12)}$, cujas normas buscavam seus direitos e, ainda, 0 Estatuto da Criança e do Adolescente $(E C A)^{(13,14)}$. O público-alvo do PROSAD são todos os adolescentes brasileiros. No programa é destacada a necessidade de considerar as características das diferentes realidades locais. As ideias expressas nas normativas do programa reconhecem teoricamente a adolescência como um fenômeno socialmente construído(14).

É importante refletir também sobre a morbidade e as causas de internação entre os jovens, pois é comum referências a essa população como aquela que menos adoece ou procura os serviços de saúde. No entanto, os dados sobre internações nessa faixa etária correspondem a aproximadamente $11 \%$ do total das internações no Brasil, especialmente devido à gravidez e causas externas. Além disso, aumentam as estatísticas de mortes por violência, uso de drogas, infecções sexualmente transmissíveis (IST), população de rua e gestações não planejadas. As ações que fazem parte da atenção dedicada a essa fase da vida exigem um cuidado qualificado, atento às necessidades específicas e vulnerabilidades que esse grupo apresenta. O adoecer do jovem preocupa, principalmente, as áreas da saúde e educação, devendo-se buscar, num esforço conjunto, desenvolver projetos com o objetivo de proporcionar aos adolescentes uma transição saudável da infância para idade adulta ${ }^{(15)}$.

De acordo com o art. 19 da Lei n. ${ }^{0} 12.852$, de 5 de agosto de 2013, que institui o Estatuto da Juventude e dispõe sobre os direitos dos jovens, os princípios e diretrizes das políticas públicas de juventude e o Sistema Nacional de Juventude - SINAJUVE, o jovem tem direito à saúde e à qualidade de vida, considerando suas especificidades na dimensão da prevenção, promoção, proteção e recuperação da saúde de forma integral( ${ }^{(9)}$.

Considerando que as fases da adolescência e da juventude são afetadas por esses vários fatores, intervindo diretamente na saúde e qualidade de vida, é relevante a promoção de pesquisas com esse público, pois poderão colaborar para uma compreensão mais aprofundada da situação em que se encontram, a fim de fortalecer ações que possam melhorar a situação que abrange essa população.

Diante desse contexto, questiona-se se os jovens e adolescentes têm conhecimento do que são saúde e qualidade de vida.

Dessa forma, o objetivo deste trabalho foi conhecer a percepção que jovens e adolescentes têm sobre saúde e qualidade de vida.

\section{MÉTODOS}

Trata-se de um estudo qualitativo, desenvolvido em um distrito que faz parte do município de Orós, Ceará, Brasil, durante o mês de fevereiro de 2018. Para este estudo foi escolhida a pesquisa qualitativa por ser um método subjetivo que se baseia, principalmente, na percepção e compreensão humana ${ }^{(16)}$.

Fizeram parte do estudo adolescentes e jovens de um grupo religioso de uma igreja católica. Primeiramente, foi realizada uma reunião formal para apresentação da pesquisa e recrutamento dos adolescentes e jovens que estariam dispostos a participar. Passada a apresentação, em outro momento, o entrevistador se dirigiu às residências dos jovens e adolescentes, momento em que todos foram convidados e se dispuseram a fazer parte da pesquisa. Realizaram-se as entrevistas nos domicílios para minimizar o grau de constrangimento dos participantes. O grupo de adolescentes e jovens era composto por 14 indivíduos. Os critérios para participar foram: adolescentes e jovens de ambos os sexos, que fizessem parte do referido grupo e que morassem na cidade de Orós. Não participaram aqueles membros que não moravam no referido município, pois tais grupos religiosos são compostos espontaneamente por jovens católicos de todo o Brasil e que, por vezes, estão visitando a comunidade. Assim, três não entraram na pesquisa, porque não eram do município, e um não concordou em participar da pesquisa por limitação do tempo, totalizando uma amostra de dez participantes.

Entende-se que a formação desses participantes é heterogênea quanto às características demográficas e socioeconômicas, possibilitando representatividade de distintos cenários. Foi preferível selecionar um grupo, por 
possibilitar o fácil acesso aos membros, simplificando as etapas da pesquisa, como convite para participação e coleta de dados. O número reduzido permitido para uma pesquisa qualitativa possibilita abordar aglomerados menores, de forma que o fechamento amostral por saturação teórica é operacionalmente definido como a suspensão de inclusão de novos participantes quando os dados obtidos passam a apresentar, na avaliação do pesquisador, certa redundância ou repetição( ${ }^{(17)}$. Assim, o fechamento amostral ocorreu com os dez participantes.

O levantamento dos dados ocorreu por meio de entrevista semiestruturada ${ }^{(18)}$, considerada uma estratégia ideal em pesquisa qualitativa. Nesta, é elaborado previamente um roteiro contendo os questionamentos básicos que se relacionam com o tema. Dessa forma, adotou-se tal estratégia por permitir flexibilidade de resposta aos participantes, que, durante a entrevista, iam naturalmente se socializando mais com o pesquisador, possibilitando maior relação com a temática de interesse.

As entrevistas aconteceram em um clima harmonioso, no local do domicílio que o adolescente/jovem se sentia mais à vontade para ser entrevistado. A primeira parte da entrevista consistiu na identificação dos participantes (faixa etária, estado civil, escolaridade, renda familiar, casa própria/alugada, trabalho, lazer, saúde geral e capacidade funcional). Na segunda etapa da entrevista, cada adolescente/ jovem respondeu a oito perguntas, que tinham como questão norteadora o conhecimento sobre saúde e qualidade de vida, acerca de percepção, busca por informações e locais de discussão do seu cotidiano. Além disso, questionou-se o entendimento sobre os programas de saúde direcionados aos jovens e a frequência deles na Estratégia Saúde da Família.

Transcreveram-se as gravações em documento no Microsoft Word 2013, conferindo fidedignidade e revelando fielmente os depoimentos dos entrevistados.

Procedeu-se à análise de conteúdo das falas ${ }^{(16)}$, sendo essa composta por cinco etapas: pré-análise, codificação e categorização, tratamento dos resultados, inferência e interpretação. De início, realizou-se uma leitura "flutuante", sendo realizada a organização do material para ser analisado junto com questionamentos. Logo após, realizou-se a codificação e a detecção das categorias que possuíam o mesmo sentido dentro do conteúdo encontrado. A análise focou no reconhecimento das categorias e de falas correspondentes, sendo todas destacadas em itálico entre aspas. Na interpretação, construiu-se uma síntese com autores que apresentaram ideias relacionadas ao contexto das categorias abordadas.

Assim, emergiram quatro categorias: Percepção sobre saúde e qualidade de vida; Interesses e contatos com temas relacionados à saúde e qualidade de vida; Programas de saúde para adolescentes e jovens; Uso da Estratégia Saúde da Família (ESF) pelos adolescentes e jovens.

O estudo respeitou as exigências formais contidas nas normas nacionais e internacionais regulamentadoras de pesquisas envolvendo seres humanos, sendo aprovado pelo Comitê de Ética e Pesquisa da Faculdade de Juazeiro do Norte, sob Parecer n. ${ }^{\circ} 2.244 .608$.

As respostas dos participantes tiveram as gravações autorizadas após a assinatura de Termos de Consentimento Livre Esclarecido (TCLE) pelos participantes maiores de idade, sendo que os adolescentes menores de idade assinaram Termos de Assentimento Livre Esclarecido (TALE) e seus responsáveis, o TCLE. Para assegurar o anonimato dos participantes, identificaram-se os fragmentos das falas pela letra $\mathrm{J}$, que corresponde à inicial da palavra jovem, seguida de ordenação numérica $(\mathrm{J} 01, \ldots \mathrm{J} 10)$.

\section{RESULTADOS E DISCUSSÃO}

Mediante o objetivo de conhecer a percepção que os adolescentes e jovens têm sobre saúde e qualidade de vida, elaboraram-se tópicos estruturados para melhor compreensão do leitor quanto à apresentação dos resultados.

No primeiro tópico, expõem-se os dados de identificação dos participantes do estudo. No segundo, à luz do referencial teórico, expõem-se e discutem-se as categorias temáticas que emergiram do estudo.

\section{Dados de identificação dos participantes do estudo}

Os adolescentes e jovens encontravam-se na faixa etária de 15 e 24 anos de idade, sendo sete maiores de idade. Com relação ao estado civil, todos se encontravam solteiros. A escolaridade variou entre nível médio (quatro participantes); nível técnico (um participante) e nível superior (cinco participantes). Dentre todos, apenas quatro exerciam algum tipo de trabalho remunerado e todos os entrevistados moravam com os pais em casa própria. Quanto ao lazer, oito responderam que praticavam algum tipo de atividade ou esporte. De acordo com a saúde em geral, oito acreditam estar saudáveis fisicamente, sendo que nenhum apresentou incapacidade física. 


\title{
Percepção sobre saúde e qualidade de vida
}

Nesta categoria, os entrevistados, ao serem questionados sobre o que é ter saúde e qualidade de vida, relataram as seguintes falas:

\begin{abstract}
"Qualidade de vida, eu acho que, eu acho que é... Tem a ver com ... assim, faz parte .... as duas têm um mesmo sentido. Acho que é ter de viver bem com as pessoas ao seu redor, tratar bem as pessoas, é seguir bem a sua vida, a alimentação, é fazer o que é bom, fazer coisas boas." (J01)
\end{abstract}

"É quando uma pessoa tem uma qualidade de vida melhor, né? Geralmente, ela vai ter com que, é vai ter mais recursos para cuidar da sua saúde, vai ter uma alimentação melhor, é isso." (J02)

"É, eu acredito, que seja um bem-estar físico e mental de cada indivíduo." (J08)

A primeira categoria está ligada diretamente à percepção que os adolescentes e jovens têm sobre saúde e qualidade de vida. Em uma análise geral, pode-se perceber que houve certa dificuldade de os entrevistados distinguirem o que é ter saúde e qualidade de vida, pois, para eles, ambos os termos são parecidos, ou a mesma coisa, e estão ligados diretamente.

Nas falas citadas acima, os entrevistados tiveram respostas distintas, porém não deixando de ter certa semelhança. $\mathrm{Na}$ interpretação da fala do J01 em relação ao que é ter saúde e qualidade de vida, foi possível notar que o convívio social foi a primeira coisa que ele relatou, podendo ser um dos fatores mais importantes segundo a sua percepção. Já J02 disse que é ter uma alimentação melhor. Na interpretação de J08, ele acredita que seja o bem-estar físico e mental de cada indivíduo.

Em um estudo no qual o objetivo foi avaliar a qualidade de vida de estudantes, pode-se concluir que a qualidade de vida estava presente na maioria dos entrevistados. Contudo é importante refletir que se trata de uma população jovem que, rotineiramente, enfrenta processos transformadores, tanto físicos como sociais ${ }^{(19)}$.

Em relação à alimentação como relevante para ter saúde, os adolescentes têm conhecimento sobre alimentação e sabem dos problemas que alimentos de baixa qualidade causam, mas a própria adolescência influencia os maus hábitos alimentares, devido ao início de um maior engajamento social(20).

Uma análise sobre a percepção da prática alimentar saudável de adolescentes em uma escola do interior de Pernambuco, no Nordeste do Brasil, identificou que, apesar de os alunos apresentarem conhecimentos sobre alimentação saudável, isso não significou que eles os colocavam em prática. Possivelmente, isso se deve aos fatores que interferem em suas escolhas alimentares, como as relações sociais( ${ }^{(21)}$.

A qualidade de vida ligada à saúde pode ser influenciada por vários parâmetros que dizem respeito ao bem-estar em geral e ao bem-estar dos jovens e dos adolescentes. Em um estudo ${ }^{(22)}$ que objetivou avaliar a percepção dos pais e cuidadores com relação ao impacto da má oclusão na qualidade de vida relacionada à saúde bucal (QVRSB) de adolescentes, pôde-se concluir que os pais ou cuidadores perceberam um impacto negativo da QVRSB nos adolescentes, sendo devido ao problema orofacial. Quanto mais grave a má oclusão que o adolescente apresentava, mais adverso e negativo era o impacto que essa condição provocava na qualidade de vida do adolescente, confirmando a fala do $\mathrm{J} 08$ do presente estudo, que relata o bem-estar físico em sua percepção com relação a esta categoria.

Foi revelada, em uma revisão sistemática de literatura ${ }^{(23)}$, que a saúde e a qualidade de vida dos adolescentes, nos últimos três anos, estão presentes em pesquisas realizadas na América e na Europa, e a maioria avalia a qualidade de vida em adolescentes com alguma doença. Mostrando, assim, que a promoção da saúde dos jovens e adolescentes não está sendo investigada em sua amplitude, como deveria, e que o cuidado com esse público se torna presente apenas quando existe algum agravo presente:

"Eu tenho, né, porque, como eu já disse, busco a minha saúde; porque tenho um lugar reservado para mim, pessoas que se importam comigo, então eu creio que sim." (J04)

"Eu acho que sim, tipo assim, da parte de fazer exame, fazer check-up a cada seis meses, tenho uma boa saúde, e tipo uma boa qualidade de vida, na questão de, tipo, tenho uma boa alimentação, alimentação balanceada, e não ser sedentária, eu acho uma boa saúde por causa disso." (J05)

"Não, já fiz vários exames, tenho várias doenças, gastrite e minha alimentação influencia diretamente nisso, porque é para passar seis meses de dieta, eu costumo não fazer isso. Acredito que não tenho uma boa saúde." (J08)

De acordo com os resultados desta categoria, os entrevistados têm uma percepção reducionista de sua saúde e qualidade de vida, tornando a percepção importante para a própria compreensão do meio em que vive e de como vive o jovem e o adolescente. 
Apesar do J08 não ter sido positivo em sua resposta, ele mostra a consciência que se deve ter sobre seus atos, e que os hábitos influenciam na saúde e qualidade de vida quando relata que não cumpre as orientações médicas que correspondem ao tratamento de sua patologia.

Nas falas contempladas nesta segunda categoria, o J05 e o J08 citaram que a alimentação tem influência em uma boa saúde e qualidade de vida. Os jovens acreditam que o incentivo da família em sua alimentação tem uma grande importância, pois a família e, principalmente, a mãe atua diretamente no preparo, compra e controle das escolhas dos alimentos ${ }^{(19)}$.

A saúde do adolescente e do jovem não é um tema muito pertinente nos campos de estudo, pois, de acordo com a Organização Mundial da Saúde, a população adolescente é considerada saudável mesmo alguns passando por diferentes tipos de doenças. De um modo geral, problemas de saúde durante a adolescência estão ligados a com quem eles vivem, à alimentação, ao sedentarismo, ao convívio social, entre outros aspectos, que podem ser prevenidos com orientações corretas. O público adolescente transporta consigo esses preconceitos devido, também, sua maioria ter superado as principais causas de doença e morte da infância ${ }^{(24)}$. Contudo, sendo a população jovem/ adolescente considerada vulnerável em vários contextos sociais e da saúde, os profissionais podem auxiliar na construção de estratégias para a promoção da convivência familiar e comunitária de adolescentes. $E$, para que isso aconteça, são necessárias políticas e ações coletivas que ajudem a reduzir riscos e a melhorar suas condições de vida e saúde ${ }^{(25)}$.

Em um estudo transversal(26), com 807 adolescentes de escolas públicas e privadas, objetivando avaliar a percepção de qualidade de vida relacionada à saúde (QVRS) de adolescentes escolares, concluiu-se que, quanto mais velhos os adolescentes e com menor posse de bens, apresentavam valores mais baixos de saúde e qualidade de vida em quase todos os parâmetros.

Para um bom desenvolvimento, o adolescente e o jovem precisam de um equilíbrio entre aspectos psicológicos e socioambientais, associando-se, também, as condições físicas, não estando pautada unicamente na garantia de sobrevivência ou no cuidado de problemas denominados orgânicos ${ }^{(27)}$.

\section{Interesses e contatos com temas relacionados à saúde e qualidade de vida}

Quando indagados por seus interesses ou algum tipo de contato relacionado a temas como saúde e qualidade de vida, os jovens e adolescentes responderam da seguinte forma:

"Sim, muito importante, programa de televisão, é difícil eu assistir. Mas eu sempre gosto de ler na internet, eu sempre gosto, procuro, fico procurando essas coisas, que eu gosto muito dessa área da saúde, então, eu procuro estar na internet, não gosto mesmo de estar assistindo televisão. Essas coisas, não." (J02)

"Não, assim, na minha instituição de ensino só era abordado tema sobre saúde na parte de alimentação, bulimia, anorexia. Mas, a parte da dieta, para se ter uma boa qualidade de vida, não era bem abordado. E, na minha casa, é mais abordada a questão de tipo do cardápio para saber o que é melhor para a gente." (J05)

"Não, nem em casa, nem na instituição. Normalmente, na instituição tem mais, [mas] por conta do meu curso não ser baseado em saúde, a gente não vê muito, não." (J09)

De acordo com o que foi observado nas entrevistas acima, pode-se perceber interesse dos entrevistados e o contato que os jovens e adolescentes têm com temas relacionados à saúde e à qualidade de vida. Mesmo alguns não tendo contato com esse tipo de assunto em casa, de alguma forma, procuram se informar sobre essas temáticas importantes.

Nas três falas relatadas, os jovens apontam seus interesses e contatos com temas relacionados à saúde e à qualidade de vida em sua casa, instituição de ensino ou outros lugares que frequentam, ou se assistem algum tipo de programa.

Acredita-se que a maioria dos jovens e adolescentes passa a maior parte do seu dia em instituições de ensino. Desde crianças, eles têm contato com esses locais educacionais, por isso a importância de usar esses ambientes como pontos estratégicos para transmitir informações sobre saúde e qualidade de vida. Os variados métodos de educação podem despertar nos jovens o interesse por atividades que fogem do seu cotidiano e que são capazes de despertar a sensação de realização e prazer. A educação em saúde é uma ação de grande importância nas vidas dos jovens e adolescentes, pois tem ação preventiva, social e educativa(28).

Em um estudo com adolescentes do sexo feminino de um lar de adoção há o relato que o uso de oficinas pedagógicas foi primordial para o seu desenvolvimento, pois permitiu a participação ativa das jovens e possibilitou reflexões sobre saúde e bem-estar, concluindo que as participantes apresentaram uma percepção positiva de 
acordo com os parâmetros do instrumento utilizado ${ }^{(29)}$. Os determinantes que compõem a vida do ser humano: determinantes sociais; culturais; políticos e econômicos; de saúde da população e condições de vida; devem ser considerados quando se realizam atividades educativas com jovens ${ }^{(30)}$.

\section{Programas de saúde para jovens e adolescente}

Nesta categoria os indivíduos ao serem questionados sobre algum tipo de programa de saúde voltado para adolescentes e jovens no distrito onde moram, e se eles influenciam de alguma forma em sua vida, os entrevistados responderam:

"Digamos que, sim, em escola, não é, onde tem colega que estuda comigo, e eu creio que pessoas que estudam na mesma escola que eu também têm. Agora não mais, já tiveram, programa, acho que é Saúde na escola, onde buscam realizar algo, digamos, é, procura interagir na sua vida, que nem eu já disse, tentam buscar algo para interferir na sua vida, seja de bom, seja de ruim." ( $\mathrm{J}$ 04)

"Não, não conheço nenhum programa e não influencia por não ter." (J08)

"Não tem nenhum programa não, por aqui tem não." (J 10)

Como demonstrado nas falas selecionadas acima, os participantes não sabiam da existência de programas voltados para a saúde dos jovens e adolescentes no distrito em que residem, embora uma minoria já tenha ouvido falar de algum programa. Com isso, pode-se perceber que esses programas não estão fazendo parte da vida dos jovens e adolescentes da localidade investigada, pois todos passaram pelas mesmas escolas e pela mesma rede de atenção básica.

Há necessidade de se discutir com os jovens e adolescentes a existência das redes de apoio voltadas diretamente a eles, ressaltando a importância do acompanhamento contínuo pela área da saúde/educação. As redes de apoio ao jovem e adolescente atuam no desenvolvimento social e intelectual, apoiando o convívio em grupo entre os jovens e a família, tendo em vista que esta faz parte do seu cotidiano ${ }^{(31)}$.

O Programa Saúde nas Escolas (PSE), instituído pelo Decreto Presidencial n. ${ }^{\circ} 6.286$, em 2007, é um exemplo de política intersetorial dos Ministérios da Saúde e da Educação. Esse programa tem o objetivo de melhorar a qualidade de vida de todos os segmentos populacionais que frequentam a rede escolar pública, avaliando as condições de saúde da população escolar, promovendo práticas em saúde e prevenção de doenças, até a capacitação continuada de educadores e profissionais da saúde, e o monitoramento das ações do programa ${ }^{(32)}$.

Um estudo transversal concluiu que o conhecimento e o acesso aos programas para a população adolescente/ jovem são deficitários, nem a escola nem o município onde a pesquisa foi realizada estão oportunizando o atendimento esperado para os adolescentes. Esse estudo também apontou a necessidade da implantação de programas de educação sexual nas escolas onde os alunos são adolescentes e sua disposição nos serviços de saúde ${ }^{(33)}$.

As oficinas educativas possibilitam aos jovens refletirem sobre o bem-estar, atitudes, comportamentos e rotinas que influenciam na saúde e qualidade de vida. O uso desses instrumentos pedagógicos é uma forma de mediar e interagir com o público no momento da educação em saúde ${ }^{(34)}$.

\section{Uso da Estratégia Saúde da Família (ESF) pelos jovens e adolescentes}

Nesta categoria, os entrevistados, ao se depararem com o questionamento sobre o uso da ESF no distrito onde residem, foram bastante sucintos, rápidos e diretos. Ao término da pergunta relacionada a esta temática os entrevistados responderam com as seguintes falas:

"É muito difícil eu frequentar. Às vezes, a gente frequenta só para fazer alguns exames de rotina, não é? Fora isso, não tem nenhum motivo de ir lá." (J01)

"Assim, é mais raro eu ir, mas de vez em quando, mais raramente, eu vou. mas quando eu vou, assim, é mais o básico, gripe, dentista, essas coisas." (J06)

"Dificilmente, eu vou. Eu acho que estou bem de saúde e não vou." (J10)

De acordo com os jovens e adolescentes entrevistados, o uso da ESF por eles é apenas para os cuidados básicos, como vacinação, gripes e idas ao cirurgião-dentista. Pode-se perceber que a frequência com que eles participam da ESF é muito baixa, podendo ser reposta à falta de um melhor acompanhamento e à falta de programas mais específicos, que abordem um cuidado mais ampliado para o público dessa faixa etária.

Em relação aos cuidados com a saúde, é necessário que o adolescente/jovem participe dos serviços da Atenção Primária de Saúde e que possa ter expectativas sobre o profissional e o seu atendimento, pois com isso haverá 
uma ampliação do acesso e cuidado da saúde e da qualidade de vida do jovem, consolidando a atenção integral a esse público etário ${ }^{(35)}$. É fundamental a organização periódica de atividades e ações voltadas para o público jovem, sendo responsabilidade de uma equipe multiprofissional o preenchimento dessas lacunas na atenção à saúde e qualidade de vida do jovem e adolescente ${ }^{(36)}$.

Constata-se que os adolescentes e jovens não têm sido atendidos em suas necessidades de saúde Para os adolescentes e jovens terem acesso aos serviços de cuidados e promoção à saúde, faz-se necessário uma organização prévia. Destacam-se alguns pontos indispensáveis para a participação do jovem na ESF: a estrutura física do local; educação permanente da equipe multidisciplinar e profissional; equipamentos adequados para o público usuário, obedecendo a realidade de cada serviço, como também as necessidades da população jovem/ adolescente ${ }^{(36)}$.

O processo de adolescer e a juventude apresentam várias fragilidades, não podendo, assim, seguir apenas uma única linha básica, sem a junção de outros serviços de abordagem ao jovem e adolescente. Esse grupo etário, identificado por suas complexidades, necessitam de políticas públicas e assistenciais que abordem vários referenciais necessários para uma promoção da saúde $\operatorname{adequada}^{(37)}$.

Assim, os resultados do presente estudo sugerem a necessidade de que novas pesquisas sejam realizadas nessa área, no sentido de contribuir para a implementação de políticas públicas vigentes, como a Política Nacional de Promoção da Saúde ${ }^{(7)}$ associada à Política de Atenção Integral à Saúde do Adolescente e do Jovem ${ }^{(12)}$, contribuindo para a saúde coletiva.

As limitações do atual estudo são referentes à disponibilidade dos jovens e adolescentes para a coleta de dados, visto que a vida dinâmica, o trabalho e os estudos restringiram os horários disponíveis para a realização das entrevistas. No entanto os obstáculos foram superados após várias tentativas e idas a seus domicílios. Uma das estratégias de contato foi a utilização de aplicativos de redes sociais. O estudo também pode ser aplicado em outras áreas que os adolescentes frequentam, como escolas e na Atenção Primária à Saúde.

\section{CONSIDERAÇÕES FINAIS}

A saúde e qualidade de vida puderam ser entendidas pelos jovens e adolescentes como algo positivo e dinâmico, sendo capturadas percepções amplas e diversificadas sobre a temática. Há necessidade, contudo, da realização de mais estudos sobre a qualidade de atendimento em saúde entre jovens frequentadores da atenção básica.

Aprimorar a adesão à assistência de saúde por parte de adolescentes e jovens deve ser o foco das políticas públicas. As estratégias devem considerar como prioridade a educação em saúde durante o acompanhamento do adolescente e jovem, pois observa-se que não é um grupo etário que tem prioridade nas equipes de saúde da família.

\section{CONFLITOS DE INTERESSE}

Os autores deste trabalho afirmam não haver conflitos de interesses de nenhuma natureza a serem declarados.

\section{CONTRIBUIÇÕES}

Uenia da Silva Brito contribuiu com a elaboração e delineamento do estudo; aquisição, análise e interpretação de dados; e a redação do manuscrito. Elida Mara Braga Rocha contribuiu com a elaboração e delineamento do estudo; e redação e/ou revisão do manuscrito.

\section{REFERENNCIAS}

1. Conselho Nacional de Saúde (BR). Relatório final. Oitava Conferência Nacional de Saúde [Internet]. Brasília: Conselho Nacional de Saúde; 1986 [acesso em 2017 Abr 01]. Disponível em: www.conselho.saúde.gov.br/ biblioteca/Relatorios.htm

2. World Health Organization Quality of Life. The World Health Organization Quality of Life assessment (WHOQOL): position paper from the World Health Organization. Soc Sci Med. 1995;41(10):1403-9.

3. Brasil. Constituição da República Federativa do Brasil de 1988 [Internet]. Brasília: Senado Federal; 1988 [acesso em 2019 Jun 20]. Disponível em: http://www.planalto.gov.br/ccivil_03/constituicao/ constituicaocompilado.htm 
4. Dias MSA, Oliveira IP, Silva LMS, Vasconcelos MIO, Machado MFAS, Forte FDS, et al. Política nacional de promoção da saúde: um estudo de avaliabilidade em uma região de saúde no Brasil. Ciênc Saúde Colet [Internet]. 2018 [acesso em 2019 Maio 28];23(1):103-14. Disponível em: http://www.scielo.br/scielo. php?script=sci_arttext\&pid=S1413-81232018000100103\&Ing=en

5. Malta DC, Morais OL Neto, Silva MMA, Rocha D, Castro AM, Reis AAC, et al. Política nacional de promoção da saúde (PNPS): capítulos de uma caminhada ainda em construção. Ciên Saúde Colet [Internet]. 2016 [acesso em 2019 Maio 23];21(6):1683-94. Disponível em: http://www.scielo.br/scielo.php?script=sci_ arttext\&pid=S1413-81232016000601683\&lng=en

6. Vasconcelos MIO, Queiroz MVO, Cavalcante ASP, Barreto RMA, Ribeiro MA, Bastos IB. Análise de projetos PET-Saúde com enfoque na saúde do adolescente. Rev Bras Pesq Saúde. 2018;20(1):32-40.

7. Ministério da Saúde (BR). Política Nacional de Promoção da Saúde. $3^{a}$ ed. Brasília: Ministério da Saúde; 2010.

8. Ministério da Saúde (BR). Secretaria de Atenção à Saúde. Área de Saúde do Adolescente e do Jovem. Marco legal: saúde, um direito de adolescentes. Brasília: Ministério da Saúde; 2005.

9. Brasil. Lei $n^{\circ} 12.852$, de 5 de agosto de 2013. Institui o Estatuto da Juventude e dispõe sobre os direitos dos jovens, os princípios e diretrizes das políticas públicas de juventude e o Sistema Nacional de Juventude SINAJUVE. Diário Oficial da União; Brasília, 5 de agosto de 2013.

10. Almeida IS, Rodrigues BMRD, Simões SMF. O adolescer... um vir a ser. Adolesc Saúde [Internet]. 2007 [acesso em 2018 Abr 13];4(3):24-8. Disponível em: http://www.adolescenciaesaude.com/detalhe_artigo. asp?id=95\#

11. Cohen, D. Quién decide? El adolescente como agente moral. Perspect Bioéticas. 2003;7(14):55-68.

12. Ministério da Saúde (BR). Secretaria de Atenção em Saúde. Departamento de Ações Programáticas Estratégicas. Área técnica de saúde do adolescente e do jovem. Diretrizes nacionais para a atenção integral à saúde de adolescentes e jovens na promoção, proteção e recuperação da saúde. Brasília: Ministério da Saúde; 2010.

13. Brasil. Lei $n^{\circ} 8.069$, de 13 de julho de 1990. Dispõe sobre o Estatuto da Criança e do Adolescente e dá outras providências. Diário Oficial da União; Brasília, 13 de julho 1990.

14. Jager ME, Batista FA, Perrone CM, Santos SS, Dias ACGD. O adolescente no contexto da saúde pública brasileira: reflexões sobre o PROSAD. Psicol Estud [Internet]. 2014 [acesso em 2019 Abr 24];19(2):211-21. Disponível em: http://www.scielo.br/scielo.php?pid=s1413-73722014000200005\&script=sci_abstract\&tlng=pt

15. Assis SG, Avanci JQ, Duarte CS. Adolescência e saúde coletiva: entre o risco e o protagonismo juvenil. Cien Saúde Colet [Internet]. 2015 [acesso em 2019 Maio 23];20(11):3296. Disponível em: http://www.scielo.br/ scielo.php?script=sci_arttext\&pid=S1413-81232015001103296\&lng=pt

16. Minayo MCS. O desafio do conhecimento: pesquisa qualitativa em saúde. São Paulo: Hucitec; 2013.

17. Denzin NK, Lincoln YS, editores. Handbook of qualitative research. Thousand Oaks: Sage Publications; 1994.

18. Boni V, Quaresma SJ. Aprendendo a entrevistar: como fazer entrevistas em Ciências Sociais. Rev Eletrônica Pós-Graduandos Sociol Polit UFSC. 2005;2(1):68-80.

19. Baraldi S, Bampi LNS, Pereira MF, Guilhem DB, Mariath AB, Campos ACO. Avaliação da qualidade de vida de estudantes de nutrição. Trab Educ Saúde [Internet]. 2015 [acesso 2019 Maio 16];13(2):515-31. Disponível em: http://www.scielo.br/scielo.php?pid=S1981-77462015000200515\&script=sci_abstract\&tlng=pt

20. Silva JG, Teixeira MLO, Ferreira MA. Alimentação na adolescência e as relações com a saúde do adolescente. Texto \& Contexto Enferm [Internet]. 2014 [acesso em 2019 Maio 16];23(4):1095-1103. Disponível em: http://www.scielo.br/pdf/tce/v23n4/pt_0104-0707-tce-23-04-01095.pdf

21. Silva DCA, Frazão IS, Osório MM, Vasconcelos MGL. Percepção de adolescentes sobre a prática de alimentação saudável. Ciênc Saúde Colet [Internet]. 2015 [acesso em 2019 Maio 20];20(11):299-330. Disponível em: http://www.scielo.br/scielo.php?script=sci_arttext\&pid=S1413-81232015001103299\&lng=en

22. Abreu LG, Melgaço CA, Abreu MH, Lages EMB, Paiva SM. Perception of parents and caregivers regarding 
the impact of malocclusion on adolescents' quality of life: a cross-sectional study. Dental Press J Orthod [Internet]. 2016 [acesso em Maio 20];21(6):74-81. Disponível em: http://www.scielo.br/scielo.php?script=sci_ arttext\&pid=S2176-94512016000600074\&lng=en

23. Higuita LF, Cardona JA. Instrumentos de evaluación de la calidad de vida relacionada con la salud del adolescente. Hacia Promoc Salud [Internet]. 2015 [acesso em 2019 Maio 20];20(2):27-42. Disponível em: https://www.sciencedirect.com/science/article/pii/S1695403301775169

24. Organización Mundial de La Salud. Adolescentes: riesgos para la salud y soluciones [internet]. 2017 [acesso em 2018 Mar 25]. Disponível em: http://www.who.int/mediacentre/factsheets/fs345/es/

25. Carlos DM, Ferriani MGC, Esteves MR, Silva LMP, Scatena L. Social support from the perspective of adolescent victims of domestic violence. Rev Esc Enferm USP [Internet]. 2014 [acesso em 2019 Maio 20];48(4):610-7. Disponível em: http://www.scielo.br/pdf/reeusp/v48n4/0080-6234-reeusp-48-04-610.pdf

26. Agathão BT, Michael ER, Moraes CL. Qualidade de vida relacionada à saúde de adolescentes escolares. Ciên Saúde Colet [Internet]. 2018 [acesso em 2019 Maio 21];23(2):659-68. Disponível: http://www.scielo.br/ scielo.php?script=sci_arttext\&pid=S1413-81232018000200659\&Ing=en

27. Senna SRCM, Dessen MA. Reflexões sobre a saúde do adolescente brasileiro. Psicol Saúde Doenças [Internet]. 2015 [acesso em 2019 Maio 21];16(2):217-29. Disponível em: https://www.sp-ps.pt/downloads/ download_jornal/392

28. Ribeiro WA, Andrade M, Cirino HP, Teixeira JM, Martins LM, Mariano ES. Adolescência, tabaco, álcool e drogas: uma revisão no olhar preventivo da educação em saúde na ESF. Revista Pró-UniverSUS [Internet]. 2018 [acesso em 2019 Maio 25];09(1):02-06. Disponível em: http://editora.universidadedevassouras.edu.br/ index.php/RPU/article/view/1115

29. Guerin CS, Coutinho C, Damasceno FM, Soares NM, Frigo JP, Soares LM. Promovendo educação em saúde no espaço não formal de aprendizagem. Rev Bras Promoç Saúde [Internet]. 2017 [acesso em 2019 Maio 23];30(1):5-12. Disponível em: https://periodicos.unifor.br/RBPS/article/view/5801

30. Costa RF, Zeitoune RCG, Queiroz MVO, García CIG, García MJR. Redes de apoio ao adolescente no contexto do cuidado à saúde: interface entre saúde, família e educação. Rev Esc Enferm USP [Internet]. 2015 [acesso em 2019 Maio 23];49(5):741-7. Disponível em: http://www.scielo.br/scielo.php?script=sci_ arttext\&pid=S0080-62342015000500741\&lng=en

31. Gimenez FVM, Higa EFR, Duarte MTC, Tonete VLP. Análise do projeto saúde e prevenção nas escolas: contribuições à gestão intersetorial. Rev Enferm UFPE [Internet]. 2014 [acesso em $2017 \mathrm{Mar}$ 23];8(8):2770-80. Disponível em: http://www.revista.ufpe.br/revistaenfermagem/index.php/revista/article/ download/6635/10038

32. Vieira RP, Gomes SHP, Machado MFAS, Bezerra IMP, Machado CA. Participation of adolescents in the family health strategy from the theoretical-methodological structure of an enabler to participation. Rev Lat Am Enfermagem [Internet]. 2014 [acesso em 2019 Maio 25];22(2):309-16. Disponível em: http://www.scielo.br/ scielo.php?script=sci_arttext\&pid=S0104-11692014000200309\&Ing=en,

33. Rolim SR, Bielenki CRZ, Béria JU, Schermann LB, Santos AMPV, Arossi GA. Conhecimento e acesso aos programas de educação sexual e prevenção da Aids: um estudo com adolescentes escolares. Aletheia [Internet]. 2016 [acesso em 2019 Maio 25];49(2):110-21. Disponível em: http://pepsic.bvsalud.org/scielo. php?script=sci_arttext\&pid=S1413-03942016000200011\&lng=pt

34. Guerin CS, Coutinho C, Damaceno FM, Soares NM, Frigo JP, Soares LM. Promovendo educação em saúde no espaço não formal de aprendizagem. Rev Bras Promoç Saúde [Internet]. 2017 [acesso em 2019 Maio 25];30(1):5-12. Disponível em: https://periodicos.unifor.br/RBPS/article/view/5801/pdf. http://dx.doi. org/10.5020/18061230.2017.p5

35. Duarte SJH, Oliveira AD, Morato MS, Morita LHM. Atuação multidisciplinar à saúde do adolescente na atenção primária à saúde. Arq Ciências Saúde UNIPAR [Internet]. 2014 [acesso em 2019 Maio 26];18(1):236. Disponível em: http://revistas.unipar.br/index.php/saude/article/download/5154/2980

36. Silva CSO, Barbosa DA, Barbosa IA, Cruz IM, Marques KP. O adolescente na estratégia saúde da família: 
uma revisão integrativa de literatura. Adolesc Saude [Internet]. 2016 [acesso em 2019 Maio 26];13(3):76-87. Disponível em: http://www.adolescenciaesaude.com/detalhe_artigo.asp?id=609

37. Silva MAI, Mello FCM, Mello DF, Ferriani MGC, Sampaio JMC, Oliveira WA. Vulnerabilidade na saúde do adolescente: questões contemporâneas. Ciên Saúde Colet [Internet]. 2014 [acesso em 2019 Maio 26];19(2):619-27. Disponível em: http://www.scielo.br/scielo.php?script=sci_arttext\&pid=S1413$81232014000200619 \&$ lng $=$ en

\section{Endereço do primeiro autor:}

Uenia da Silva Brito

Faculdade de Juazeiro do Norte - FJN

Rua São Francisco, 1224

Bairro: São Miguel

CEP: 63010-475 - Juazeiro do Norte - CE - Brasil

E-mail: ueniabrito@gmail.com

\section{Endereço para correspondência:}

Elida Mara Braga Rocha

Faculdade de Juazeiro do Norte - FJN

Núcleo de Estudos em Nutrição

Rua São Francisco, 1224

Bairro: São Miguel

CEP: 63010-475 - Juazeiro do Norte - CE - Brasil

E-mail: elida.braga@fjn.edu.br

Como citar: Brito US, Rocha EMB. Percepção de jovens e adolescentes sobre saúde e qualidade de vida. Rev Bras Promoç Saúde. 2019;32:8993. 